\title{
Meta-analyses of developing brain function in high-risk and emerged bipolar disorder
}

\author{
Moon-Soo Lee ${ }^{1,2}$, Purnima Anumagalla ${ }^{1}$, Prasanth Talluri ${ }^{1}$ and Mani N. Pavuluri ${ }^{1}$ * \\ ${ }^{1}$ Pediatric Brain Research and Intervention Center, University of Illinois at Chicago, Chicago, IL, USA \\ ${ }^{2}$ College of Medicine, Korea University, Seoul, South Korea
}

\begin{abstract}
Edited by:
Stephanie Ameis, The Hospital for Sick Children and University of

Toronto, Canada
\end{abstract}

Reviewed by:

Meng-Chuan Lai, University of

Cambridge, UK

Nicholas Neufeld, University of

Toronto, Canada

Annette Beatrix Bruehl, University of

Cambridge, UK

*Correspondence:

Mani N. Pavuluri, Pediatric Brain Research and Intervention Center,

University of Illinois at Chicago, M/C 747, 1747 West Roosevelt Road,

Chicago, IL 60608, USA

e-mail:mpavuluri@psych.uic.edu

\begin{abstract}
Objectives: Identifying early markers of brain function among those at high risk (HR) for pediatric bipolar disorder (PBD) could serve as a screening measure when children and adolescents present with subsyndromal clinical symptoms prior to the conversion to bipolar disorder. Studies on the offspring of patients with bipolar disorder who are genetically at HR have each been limited in establishing a biomarker, while an analytic review in summarizing the findings offers an improvised opportunity toward that goal.
\end{abstract}

Methods: An activation likelihood estimation (ALE) meta-analysis of mixed cognitive and emotional activities using the GingerALE software from the BrainMap Project was completed. The meta-analysis of all $\mathrm{fMRI}$ studies contained a total of 29 reports and included $\mathrm{PBD}, \mathrm{HR}$, and typically developing (TD) groups.

Results:The HR group showed significantly greater activation relative to theTD group in the right DLPFC-insular-parietal-cerebellar regions. Similarly, the HR group exhibited greater activity in the right DLPFC and insula as well as the left cerebellum compared to patients with $\mathrm{PBD}$. Patients with $\mathrm{PBD}$, relative to $T D$, showed greater activation in regions of the right amygdala, parahippocampal gyrus, medial PFC, left ventral striatum, and cerebellum and lower activation in the right VLPFC and the DLPFC.

Conclusion: The HR population showed increased activity, presumably indicating greater compensatory deployment, in relation to both the TD and the PBD, in the key cognition and emotion-processing regions, such as the DLPFC, insula, and parietal cortex. In contrast, patients with PBD, relative to HR and TD, showed decreased activity, which could indicate a decreased effort in multiple PFC regions in addition to widespread subcortical abnormalities, which are suggestive of a more entrenched disease process.

Keywords: pediatric bipolar disorder, high risk, meta-analysis, GingerALE, dorsolateral prefrontal cortex, amygdala

\section{INTRODUCTION}

The relationship between pediatric and adult bipolar disorder has been the subject of controversy. It is not clear whether pediatric bipolar disorder (PBD) is the pediatric form of the typical adult bipolar disorder or an entity of its own, as bipolar disorder usually manifests differently in childhood than in adulthood. Some studies in adults have reported that a portion of adults with bipolar I disorder experienced childhood or adolescent onset, and some of them began showing symptoms even before 12 years of age $(1,2)$. Identifying early markers of brain function among those at high risk (HR) for PBD could serve as a screening measure when children and adolescents present with subsyndromal clinical symptoms prior to the conversion to bipolar disorder (pediatric or adult form). These biomarkers can also aid as a stand-alone bio-signature for the identification of risk even prior to the emergence of any clinical symptoms and could allow an opportunity to prevent the onset of full-blown illness (3). One way to begin identifying the biomarkers is to examine the brain function in the genetically HR offspring of patients with bipolar disorder. While some studies of HR have been published (4-11), due to their small sample sizes and corrections for multiple comparisons, the findings remain inconclusive.

To offer robust and reliable findings, we used a recently developed activation likelihood estimation (ALE) technique. This method assumes that the peak co-ordinates reported by each study represent the activation maps from which they are derived and uses the reported co-ordinates in voxel-wise analysis to assess the consistency of activation in any given set of studies (12-14). By performing the quantitative voxel-wise meta-analysis of already published results from the HR population and comparing them with those from the converted PBD and typically developing (TD) youth, we can provide objective, unbiased, and statistically based quantified evidence.

Ideally, a separate meta-analysis would be conducted for each individual domain, such as emotion processing or attention, as they relate to bipolar disorder diathesis. However, given the infancy of the current literature regarding HR patients, this is not practical, as no individual construct has included a sufficient number of studies to date. Instead, it is more feasible to study the commonalities probed across multiple domains in a systematic and 


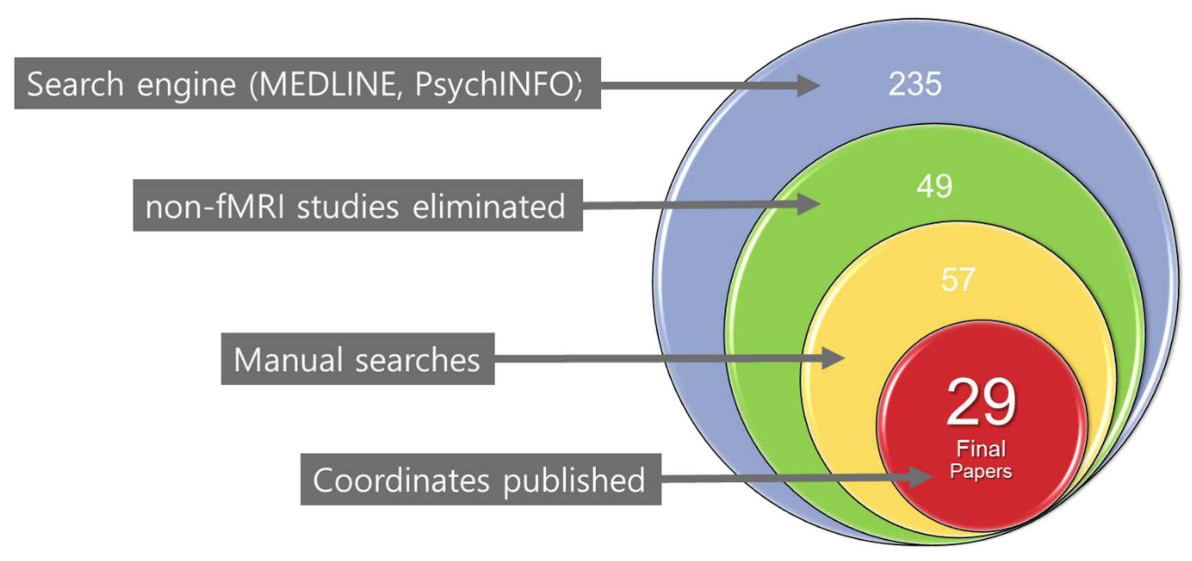

FIGURE 1 | Flow chart of the literature search for included studies

statistically driven fashion. There is a certain advantage to combining all the studies that include multi-domain probes. First, the brain does not work in isolation across individual domains; therefore, it is necessary to examine the brain's function as a whole while it is engaged in affective, cognitive, and motor control tasks (15). Furthermore, pooling several pilot studies produces an exploratory power of how the brain functions in a larger sample, eventually offering the possibility of correlating the results with the clinical manifestations of domains and disorders presenting with combined affective, cognitive, and motoric symptoms (16). This approach is a segue into future studies that can explore the interface of multiple domain functions in individual studies.

We consider emotional systems and circuits, in illness or wellness, to be closely linked to cognitive and motor control circuits of attention, working memory, and response inhibition (17). These systems interface at three tiers as shown in animal (18) and human studies of PBD (19): (1) at the prefrontal level between the ventrolateral prefrontal cortex [VLPFC; inferior frontal gyrus; Brodmann areas (BAs) 45, 47] and the dorsolateral prefrontal cortex (DLPFC; middle frontal gyrus; BAs 9, 9, 46), (2) at the intermediary cortex in the anterior cingulate cortex (ACC), such as between the dorsal (BA 32) and pregenual ACC (BA 24), and (3) at the subcortical level between the amygdala and striatum (19). While we could not determine which probe or domain dysfunction would contribute to activity in any given co-ordinate in this meta-analysis, we developed our hypotheses based on knowledge derived from the emerging literature. Emotion-processing tasks probing the affective systems entered into our meta-analysis would contribute to the increased prefrontal activity at the interface of VLPFC and DLPFC in HR and the decreased activity in PBD relative to TD (19). Increased subcortical amygdala activity would be a specific marker of PBD (20) relative to HR and TD. Based on our knowledge of attention and working memory task response, the DLPFC will manifest with increased activity in HR (6) and decreased activity in PBD (21), relative to TD. Impaired subcortical striatal activity would be a more entrenched specific marker of PBD's cognitive and motor dysfunction $(20,22,23)$ relative to the HR and TD groups.

\section{MATERIALS AND METHODS SEARCH STRATEGY}

We identified primary studies through a comprehensive literature search of the MEDLINE (using both free-text and MeSH search) and PsychINFO databases using the following keywords: pediatric or child or adolescent, plus bipolar disorder or highrisk or at risk, and plus functional magnetic resonance imaging or fMRI. In addition, manual searches were conducted via reference sections of review articles and individual studies to check for any missing studies that were not identified using computerized searches. There were no language restrictions; in fact, all the included manuscripts were written in English. Only fMRI studies were chosen for review. An initial list of studies was produced that included any report of fMRI studies of PBD and HR offspring published in print or online by December 31, 2013. The selection process for the final list of primary studies for the planned meta-analyses in this study was very specific. The first-level literature search yielded 235 unique published articles with 49 studies meeting the initial inclusion criteria. A further manual search leads to eight other studies. After a second-level review of these 57 studies, only 29 contained the co-ordinates essential for inclusion in our meta-analysis (Figure 1). Any ambiguity in inclusion was resolved through a consensus decision by the authors of this manuscript. Study data (e.g., co-ordinates, participant numbers, and imaging spaces) were entered and crosschecked by participating authors.

\section{SELECTION CRITERIA}

"High risk" in this project refers to adolescents who have a biological parent diagnosed with BD. We selected studies with participants whose mean age was less than 19 years. Every study that we included had participants between the ages of 7 and 18 except for the study performed by Thermenos et al. (11), where the ages ranged up to 24 . All reports included in the meta-analysis satisfied the following criteria: (1) a healthy comparison group is included, (2) the studies conducted whole-brain analyses, (3) all studies provided standard Talairach or Montreal Neurological Institute (MNI) spatial co-ordinates for the key findings, (4) 
patient participants had been diagnosed with bipolar disorder, and (5) there were at least five members in each of the participant groups. We included only those studies that reported activation foci as 3D co-ordinates in stereotactic space, examined active task constructs, and presented results for groups of participants.

Excluded manuscripts consisted of the following: (1) reviews or meta-analyses, (2) those with subject overlap, and (3) other MRI modalities (e.g., structural imaging, spectroscopy, diffusion tensor imaging, and functional connectivity studies).

\section{ACTIVATION LIKELIHOOD ESTIMATION METHODS AND PAIRWISE ALE META-ANALYSIS}

GingerALE software version (version 2.3.1) from the BrainMap project was used to conduct ALE meta-analysis of eligible studies $(13,14,43)$. Meta-analyses were performed using the revised ALE software (i.e., GingerALE 2.3). The key modification in the revised ALE software included the change from fixed-effects (convergence between foci) to random-effects inference (convergence between studies but not individual foci reported for the same study), as well as greater meta-analytic weighting for primary studies that involved more participants. In line with our goal of gaining insight on the whole brain's function through tasks that probe combined domains, we performed exploratory analyses using all eligible data in the HR offspring, BD patient, and TD groups in the pediatric age group. Conversely, we did not separate the analyses by the type of the task or the brain domain probed. This method also helped to harness sample size and power. Activation co-ordinates reported in the MNI space were converted to Talairach co-ordinates using the Lancaster transform (icbm2tal) in GingerALE. Our meta-analysis was conducted in Talairach space. Co-ordinates originally presented as MNI space were transformed into Talairach space using Lancaster transformation. For uniformity, Talairach co-ordinates expressed by the previous Brett transformation (44) were converted into MNI space and re-transformed into Talairach space. The meta-analysis was performed using pairwise ALE meta-analysis.

Pairwise ALE meta-analyses included the following comparisons at first: greater activation in $\mathrm{PBD}$ versus $\mathrm{HR}$, in $\mathrm{HR}$ versus $P B D$, in $P B D$ versus $T D$, in TD versus $P B D$, in $H R$ versus TD, and in TD versus HR. However, two pairwise ALE meta-analyses (greater activation in PBD versus $\mathrm{HR}$ and greater activation in TD versus $H R$ ) were not performed due to the lack of available data. The input co-ordinates were weighted to form estimates of activation likelihood for each intracerebral voxel. The activation likelihood of each voxel in standard space was then combined to form a statistic map of the ALE score at each voxel. Statistical significance of the ALE scores was determined by a permutation test controlling the false discovery rate (FDR) at $p<0.05$ (45). The statistic maps were thresholded by default at this critical value, and a recommended minimum cluster size was suggested from the cluster statistics. By using this minimum cluster size for the supra-threshold voxels, we can obtain the thresholded ALE image. Pairwise ALE analyses results were reported at $p=0.05$ and were whole-brain corrected. A Talairach Daemon was used for anatomical locations for significant clusters.

\section{RESULTS}

The meta-analysis of all fMRI reports included 29 studies (PBD, $\mathrm{HR}$, and TD). There was no overlap in patients who completed the same task across the selected studies. The primary studies included in the meta-analysis are listed in Table 1. Findings are summarized in Table 2 and Figure 2.

\section{HR AND TD: RECOGNIZING HIGH-RISK PARTICIPANTS}

Participants in the HR group showed significantly greater activation in the right DLPFC, insula, inferior parietal lobule, and left cerebellum relative to TD. No other group differences were found. In case of greater activation in the TD group relative to $\mathrm{HR}$, the analysis was not performed due to the lack of a large enough sample size and of experiments showing significant results.

\section{PBD AND HR: RECOGNIZING THE EMERGENCE OF THE DISORDER}

The HR group showed significant greater activation of the right DLPFC, insula, and left cerebellum than PBD. No other group differences were identified. In case of greater activation in the PBD group relative to $\mathrm{HR}$, the analysis was also not performed due to a small sample size and few experiments showing significant results.

\section{PBD AND TD: RECOGNIZING THE ILLNESS FROM WELLNESS}

Patients with PBD demonstrated greater activation in the subcortical regions of the right amygdala, the parahippocampal gyrus, the subgenual ACC, and the medial PFC, and in the left ventral striatum, VLPFC, and cerebellum relative to TD. The TD group showed greater activation in the right VLPFC, DLPFC, superior frontal gyrus, dorsal ACC, and striatum than patients with PBD.

\section{DISCUSSION}

We found the recently published developmental meta-analysis of bipolar disorder performed by Wegbreit et al. The researchers compared different age groups with bipolar disorder (youths and adults). PBD youths showed increased activation in the amygdala, the inferior frontal gyrus, and precuneus compared to bipolar disorder adults during tasks using emotional stimuli. These findings revealed that these structures are underdeveloped and work less efficiently when compared with those of adults (46). However, our meta-analysis was conducted using the comparison between participants of the same age (participants' mean age is less than 19 years). The central findings of the meta-analyses of brain function among the PBD, HR, and TD groups, during the performance of mixed cognitive and emotional activities, illustrated a coherent pattern of group differences in line with our a priori hypothesis. The HR group showed a significantly greater activation in the right DLPFC-insular-parietal-cerebellar regions relative to TD, and this may be a bio-signature - an earlier sign of potential PBD development. At the junction of the DLPFC and VLPFC regions, where prefrontal systems interface in voluntary modulation of cognition, emotion, and motor control, brain function was amplified in the HR group $(6,7)$. Large future studies of symptomatic HR population (47) and genetic HR population must be compared both at a symptomatic and brain functional level to look at the definitive predictability of symptoms and the correlation of brain activity patterns. 
Table 1 | Primary fMRI studies of participants with pediatric bipolar disorder (PBD), those at high risk (HR) for PBD, and typically developing (TD): children included in meta-analysis.

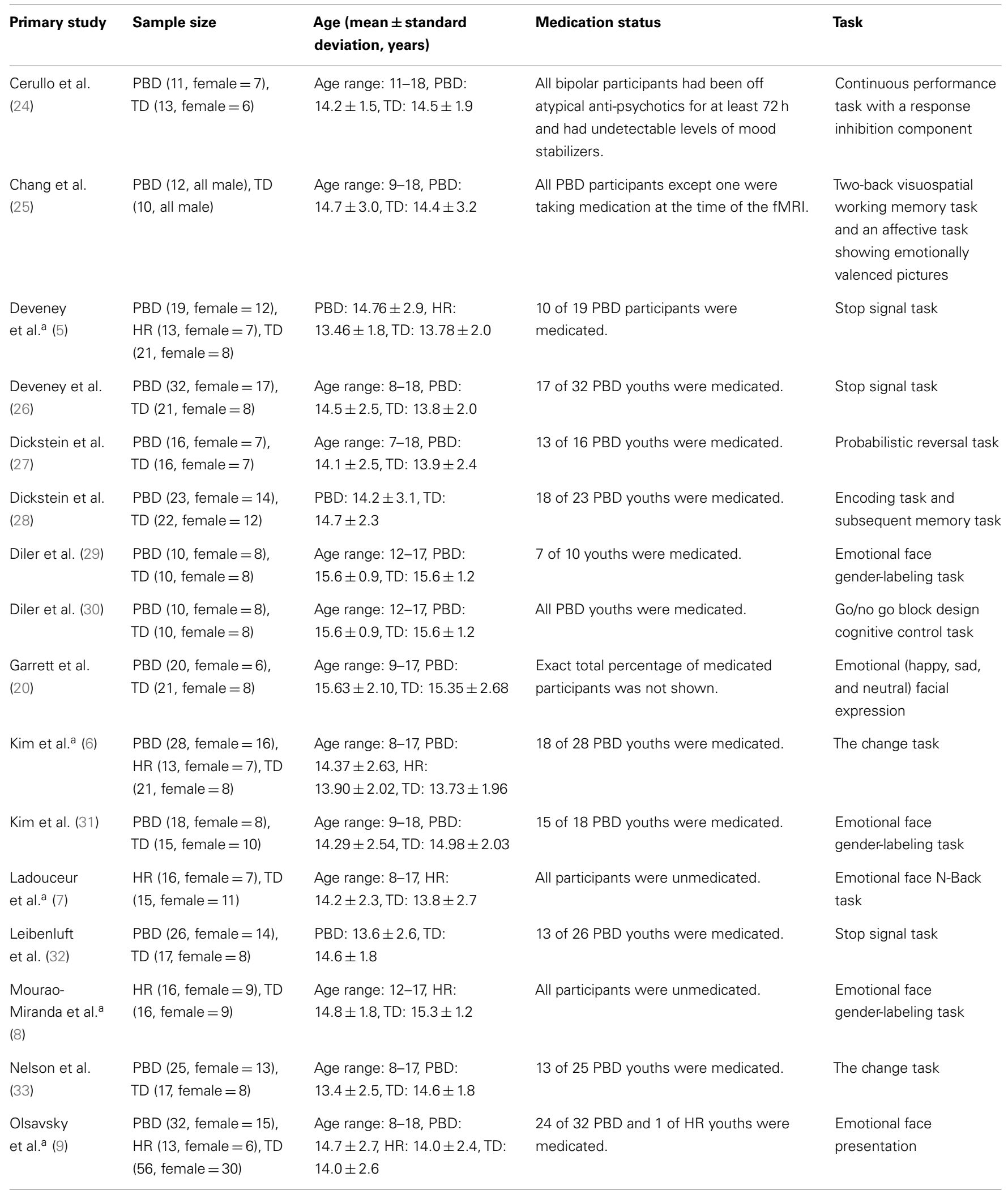


Table 1 | Continued

\begin{tabular}{|c|c|c|c|c|}
\hline Primary study & Sample size & $\begin{array}{l}\text { Age (mean } \pm \text { standard } \\
\text { deviation, years) }\end{array}$ & Medication status & Task \\
\hline $\begin{array}{l}\text { Passarotti } \\
\text { et al. (34) }\end{array}$ & $\begin{array}{l}\operatorname{PBD}(15, \text { female }=8) \\
\operatorname{TD}(15, \text { female }=8)\end{array}$ & $\begin{array}{l}\text { Age range: } 10-18, \text { PBD: } \\
13.20 \pm 2.65, \text { TD: } 14.13 \pm 3.16\end{array}$ & $\begin{array}{l}8 \text { of } 15 \text { PBD youths had been medicated } \\
\text { in the past. Patients were drug-free for at } \\
\text { least } 7 \text { days before testing. }\end{array}$ & Stop signal task \\
\hline $\begin{array}{l}\text { Passarotti } \\
\text { et al. (22) }\end{array}$ & $\begin{array}{l}\operatorname{PBD}(23, \text { female }=13) \\
\operatorname{TD}(19, \text { female }=10)\end{array}$ & $\begin{array}{l}\text { Age range: } 10-18, \mathrm{PBD}: \\
13.55 \pm 2.48, \mathrm{TD}: 13.53 \pm 3.16\end{array}$ & $\begin{array}{l}\text { All participants were medication free or } \\
\text { had a washout period of at least } 4-7 \text { days } \\
\text { before scanning. }\end{array}$ & $\begin{array}{l}\text { Emotional face N-Back } \\
\text { task }\end{array}$ \\
\hline $\begin{array}{l}\text { Passarotti } \\
\text { et al. (35) }\end{array}$ & $\begin{array}{l}\operatorname{PBD}(17, \text { female }=11) \\
\operatorname{TD}(14, \text { female }=7)\end{array}$ & $\begin{array}{l}\text { Age range: } 10-18, \mathrm{PBD}: \\
14.27 \pm 1.98, \mathrm{TD}: 14.14 \pm 2.42\end{array}$ & $\begin{array}{l}\text { All participants were medication free or } \\
\text { had a washout period. }\end{array}$ & $\begin{array}{l}\text { Emotional valence Stroop } \\
\text { task }\end{array}$ \\
\hline $\begin{array}{l}\text { Passarotti } \\
\text { et al. (36) }\end{array}$ & $\begin{array}{l}\operatorname{PBD}(17, \text { female }=12) \\
\operatorname{TD}(13, \text { female }=7)\end{array}$ & $\begin{array}{l}\text { Age range: } 10-18, \text { PBD: } \\
14.29 \pm 2.05, \text { TD: } 14.38 \pm 3.57\end{array}$ & $\begin{array}{l}\text { All patients were medication free for at } \\
\text { least } 7 \text { days prior to scanning. }\end{array}$ & $\begin{array}{l}\text { Emotional face N-Back } \\
\text { task }\end{array}$ \\
\hline $\begin{array}{l}\text { Pavuluri et al. } \\
\text { (37) }\end{array}$ & $\begin{array}{l}\operatorname{PBD}(10, \text { female }=4) \\
\operatorname{TD}(10, \text { female }=5)\end{array}$ & $\begin{array}{l}\text { Age range: } 12-18, \text { PBD: } \\
14.9 \pm 1.85, T D: 14.3 \pm 2.36\end{array}$ & All participants were unmedicated. & $\begin{array}{l}\text { Emotional face } \\
\text { presentation }\end{array}$ \\
\hline $\begin{array}{l}\text { Pavuluri et al. } \\
\text { (21) }\end{array}$ & $\begin{array}{l}\operatorname{PBD}(10, \text { female }=5) \\
\operatorname{TD}(10, \text { female }=5)\end{array}$ & $\begin{array}{l}\text { Age range: } 12-18, \text { PBD: } \\
15.2 \pm 2.0, \text { TD: } 14.3 \pm 2.1\end{array}$ & All participants were unmedicated. & $\begin{array}{l}\text { Incidental and directed } \\
\text { emotion-processing task }\end{array}$ \\
\hline $\begin{array}{l}\text { Pavuluri et al. } \\
\text { (38) }\end{array}$ & $\begin{array}{l}\operatorname{PBD}(13, \text { female }=3) \\
\operatorname{TD}(13, \text { female }=9)\end{array}$ & $\begin{array}{l}\text { Age range: } 10-18, \text { PBD: } \\
14.4 \pm 2.2, \text { TD: } 14.4 \pm 2.8\end{array}$ & $\begin{array}{l}\text { All patients were medication free for at } \\
\text { least } 4-7 \text { days prior to scanning. }\end{array}$ & Response inhibition task \\
\hline $\begin{array}{l}\text { Pavuluri et al. } \\
\text { (39) }\end{array}$ & $\begin{array}{l}\operatorname{PBD}(17, \text { female }=11) \\
\operatorname{TD}(14, \text { female }=7)\end{array}$ & $\begin{array}{l}\text { Age range: } 12-18, \mathrm{PBD}: \\
14.3 \pm 1.1, \mathrm{TD}: 14.1 \pm 2.4\end{array}$ & All participants were unmedicated. & $\begin{array}{l}\text { Pediatric affective color } \\
\text { matching task }\end{array}$ \\
\hline Rich et al. (23) & $\begin{array}{l}\operatorname{PBD}(22, \text { female }=12) \\
\operatorname{TD}(21, \text { female }=10)\end{array}$ & $\begin{array}{l}\text { Ager range: } 9-17, \mathrm{PBD}: \\
14.2 \pm 3.1, \mathrm{TD}: 14.5 \pm 2.5\end{array}$ & 18 of 22 PBD youths were medicated. & $\begin{array}{l}\text { Emotional face } \\
\text { presentation }\end{array}$ \\
\hline $\begin{array}{l}\text { Singh et al. } \\
(40)\end{array}$ & $\begin{array}{l}\text { PBD }(24, \text { female }=11) \\
\operatorname{TD}(24, \text { female }=15)\end{array}$ & $\begin{array}{l}\text { Age range: } 13-18, \text { PBD: } \\
15.7 \pm 1.7, \text { TD: } 15.0 \pm 1.4\end{array}$ & $\begin{array}{l}20 \text { of } 24 \text { PBD participants had a history of } \\
\text { medication exposure. }\end{array}$ & $\begin{array}{l}\text { Monetary incentive delay } \\
\text { task, affective priming } \\
\text { task }\end{array}$ \\
\hline $\begin{array}{l}\text { Singh et al. } \\
(41)\end{array}$ & $\begin{array}{l}\operatorname{PBD}(26, \text { female }=7) \\
\operatorname{TD}(22, \text { female }=9)\end{array}$ & $\begin{array}{l}\text { Age range: } 9-18, \text { PBD: } \\
15.4 \pm 2.37, T D: 14.3 \pm 2.33\end{array}$ & $\begin{array}{l}\text { History of medication exposure: valproic } \\
\text { acid (13), lithium (8), antidepressants (16), } \\
\text { atypical anti-psychotics (6), } \\
\text { psychostimulants (14), or more than one } \\
\text { medication (16). }\end{array}$ & $\begin{array}{l}\text { Go/no go block design } \\
\text { cognitive control task }\end{array}$ \\
\hline $\begin{array}{l}\text { Thermenos } \\
\text { et al. }{ }^{a}(11)\end{array}$ & $\begin{array}{l}\text { HR }(10, \text { female }=5), \text { TD } \\
(10, \text { female }=5)\end{array}$ & $\begin{array}{l}\text { Age range: } 13-24, \mathrm{HR}: \\
18.4 \pm 4.2, \mathrm{TD}: 17.1 \pm 1.4\end{array}$ & All participants were unmedicated. & $\begin{array}{l}\text { 2-back working memory } \\
\text { task and 0-back control } \\
\text { task }\end{array}$ \\
\hline $\begin{array}{l}\text { Weathers et al. } \\
\text { (42) }\end{array}$ & $\begin{array}{l}\operatorname{PBD}(16, \text { female }=8) \\
\operatorname{TD}(21, \text { female }=9)\end{array}$ & $\begin{array}{l}\text { PBD: } 14.65 \pm 2.19, \mathrm{TD}: \\
13.79 \pm 1.97\end{array}$ & 9 of 16 PBD youths were medicated. & Stop signal task \\
\hline
\end{tabular}

a Studies including HR groups.

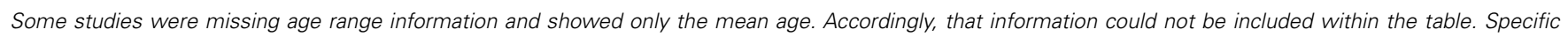

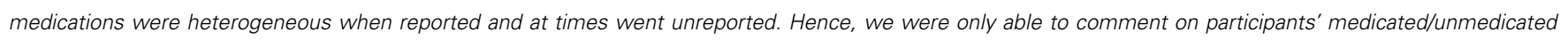
status. Similarly, the mood and affect of participants were also largely unreported and, therefore, could not be included in the table.

A repeated and important observation of hemodynamics of the fMRI studies is the increased activity in the brain that reflects increased effort (48). If one construes TD as the reference point of normative activity, then the HR group showed increased effort to get the same work done by deploying the right DLPFC-insularparietal regions relative to TD, while in $\mathrm{PBD}$, these same regions went offline relative to TD. This finding is akin to the analogy of "stretching an elastic band" with increased DLPFC activity (requiring a greater effort than TD) in the HR group, whereas those with PBD who had a more severe illness had reached a breaking point with decreased right VLPFC and DLPFC activity (with no effort to spare relative to TD). We could not explain the increased left VLPFC activity in PBD relative to TD. While such a finding is not unexpected in a meta-analytic study, it was largely based upon the 
Table 2 | Activation likelihood estimation (ALE) meta-analysis findings for fMRI studies comparing pediatric bipolar disorder (PBD) patients, participants with a high risk (HR) for PBD, and typically developing (TD) children.

\begin{tabular}{|c|c|c|c|c|c|c|c|c|}
\hline \multirow[t]{2}{*}{ Pairwise analysis } & \multirow[t]{2}{*}{ Side } & \multirow[t]{2}{*}{ Brain region } & \multirow[t]{2}{*}{ BA } & \multicolumn{3}{|c|}{ Talairach } & \multirow[t]{2}{*}{ Cluster size $\left(\mathrm{mm}^{3}\right)$} & \multirow[t]{2}{*}{ Extreme value } \\
\hline & & & & $X$ & $Y$ & $Z$ & & \\
\hline \multirow{6}{*}{$\begin{array}{l}\text { HR youths }>\text { TD youths } \\
\text { (11 experiments) }\end{array}$} & \multirow[t]{3}{*}{$L$} & \multirow[t]{3}{*}{ Cerebellum, culmen } & & -8 & -50 & -26 & \multirow[t]{2}{*}{1472} & 0.022 \\
\hline & & & & -14 & -36 & -22 & & 0.014 \\
\hline & & & & -2 & -54 & -10 & 952 & 0.021 \\
\hline & $\mathrm{R}$ & Dorsolateral prefrontal cortex & 9 & 46 & 8 & 22 & 1048 & 0.020 \\
\hline & $\mathrm{R}$ & Insular cortex & 13 & 38 & 18 & 6 & 472 & 0.014 \\
\hline & $\mathrm{R}$ & Parietal lobe, inferior parietal lobule & 40 & 32 & -46 & 42 & 464 & 0.014 \\
\hline HR youths $>$ BD youths & $\mathrm{R}$ & Dorsolateral prefrontal cortex & 9 & 46 & 8 & 22 & 1056 & 0.020 \\
\hline \multirow[t]{2}{*}{ (6 experiments) } & $L$ & Cerebellum & & -8 & -50 & -26 & 944 & 0.022 \\
\hline & $\mathrm{R}$ & Insular cortex & 13 & 38 & 18 & 6 & 496 & 0.014 \\
\hline $\mathrm{BD}>\mathrm{TD}(43$ & $\mathrm{R}$ & Amygdala, limbic lobe, parahippocampal gyrus, & & 26 & -2 & -12 & 1120 & 0.0221 \\
\hline \multirow[t]{11}{*}{ experiments) } & \multirow[t]{2}{*}{$\mathrm{R}$} & \multirow[t]{2}{*}{ Frontal lobe, medial prefrontal cortex } & \multirow[t]{2}{*}{10} & 4 & 62 & 14 & 872 & 0.030 \\
\hline & & & & 12 & 40 & 10 & 568 & 0.023 \\
\hline & $L$ & Ventral striatum & & -16 & -12 & 28 & 640 & 0.024 \\
\hline & \multirow[t]{2}{*}{$\mathrm{R}$} & \multirow[t]{2}{*}{ Somatosensory association cortex } & \multirow[t]{2}{*}{7} & 42 & -58 & 48 & 576 & 0.020 \\
\hline & & & & 2 & -64 & 56 & 392 & 0.019 \\
\hline & $L$ & Cerebellum & & -16 & -36 & -24 & 560 & 0.022 \\
\hline & \multirow[t]{3}{*}{$L$} & \multirow[t]{3}{*}{ Lentiform nucleus, putamen, lateral globus pallidus } & & -22 & 6 & -4 & 464 & 0.018 \\
\hline & & & & -12 & 4 & -6 & 368 & 0.017 \\
\hline & & & & -16 & -4 & -8 & & 0.013 \\
\hline & $L$ & Ventrolateral prefrontal cortex & 47 & -30 & 20 & -8 & 336 & 0.017 \\
\hline & $\mathrm{R}$ & Subgenual cingulate cortex & 25 & 2 & 0 & -4 & 256 & 0.016 \\
\hline TD > PBD $(21$ & $\mathrm{R}$ & Dorsal cingulate cortex & 32 & 2 & 36 & 12 & 1576 & 0.017 \\
\hline \multirow[t]{4}{*}{ experiments) } & $\mathrm{R}$ & Dorsal striatum & & 10 & 10 & 6 & 696 & 0.014 \\
\hline & $\mathrm{R}$ & Ventrolateral prefrontal cortex & 47 & 38 & 24 & -4 & 336 & 0.011 \\
\hline & $\mathrm{R}$ & Dorsolateral prefrontal cortex & 8 & 32 & 24 & 38 & 224 & 0.013 \\
\hline & $\mathrm{R}$ & Superior frontal gyrus & 10 & 24 & 48 & 2 & 216 & 0.011 \\
\hline
\end{tabular}

R: right, L: left.

participants of only one study (21). However, it can be explained by bilateral disturbances in the VLPFC in PBD, albeit with the common and prominent right-sided abnormality than the left $(32,37)$. In the end, while one can postulate with explanations consistent with repeatedly published findings, definitive interpretations are not possible in understanding the nature of abnormal hemodynamic activity. For example, decreased (5) or increased (6) activation of the striatum with failed trials cannot easily differentiate HR from PBD based on any individual study. It could be mediated by the severity of illness in case of PBD, subsyndromal symptoms in HR, type of task, or hemodynamic relationship between the striatum and the PFC control regions.

With regard to recognizing the fully formed illness, typically noted underactivity of the higher cortical regions of emotion modulation (i.e., the interfacing dyad of the right VLPFC and DLPFC in the prefrontal regions) and overactivity of the subcortical amygdala consistently reported in BD Type I participants relative to TD adolescents (19) has also emerged as a significant finding in the current meta-analyses. The VLPFC is believed to serve the dual function of emotion (49) and motor (50) control via top-down regulation of the amygdala (51) and striatum (52), respectively. The DLPFC also serves a dual function, but it is predominantly through diverse cognitive functions involving executive control, response selection, problem solving, and emotion (53), and by being closely connected to the medial PFC, VLPFC, and the subcortical regions directly (54) as well as indirectly (52). The cognitive and emotion control regions in the PFC are not able to moderate the overactive subcortical regions, a consistent finding that was further underscored in our meta-analysis. In addition to the top-down affect modulation circuitry problems, increased activity is lateralized to the left side in the evaluative medial PFC, pregenual ACC, and the striatal loop (55); furthermore, all these regions are known to be closely connected to the amygdala (56). This subcortical and medial PFC loop is the affective evaluation circuit that is overactive in PBD. These findings could explain the excessive reactivity to negative emotions reported in $\operatorname{PBD}(21,57)$ and are also in line with the concept suggested for bipolar disorder in general, including adult patients. Phillips and Swartz conceptualized bipolar disorder as multiple dysfunctions in prefrontal hippocampal-amygdala, emotion processing, 


\section{A}

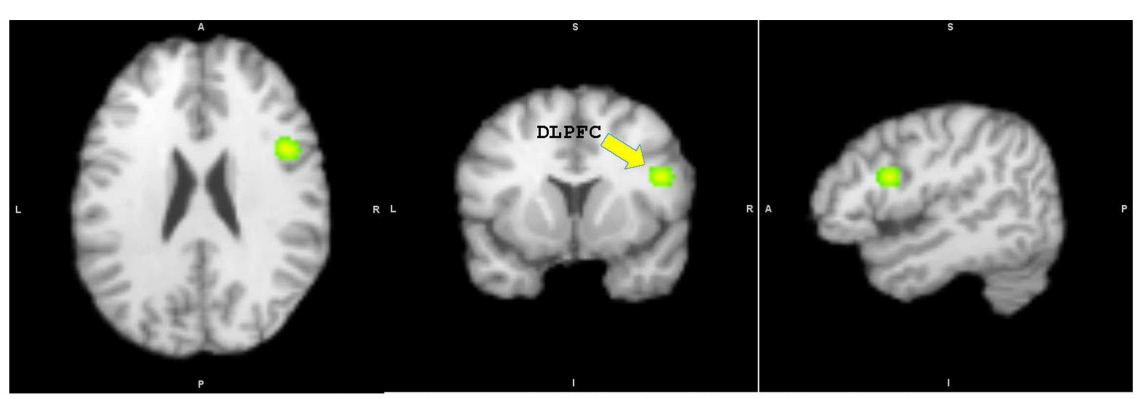

B

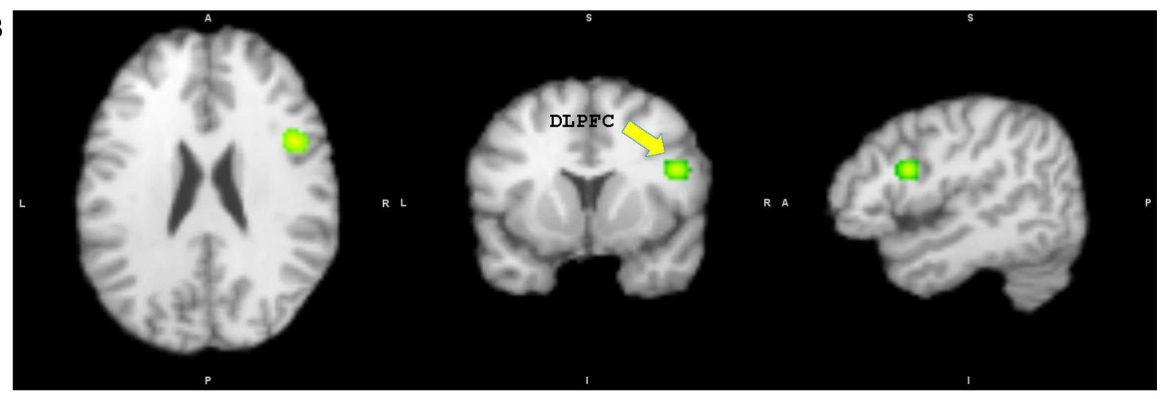

C
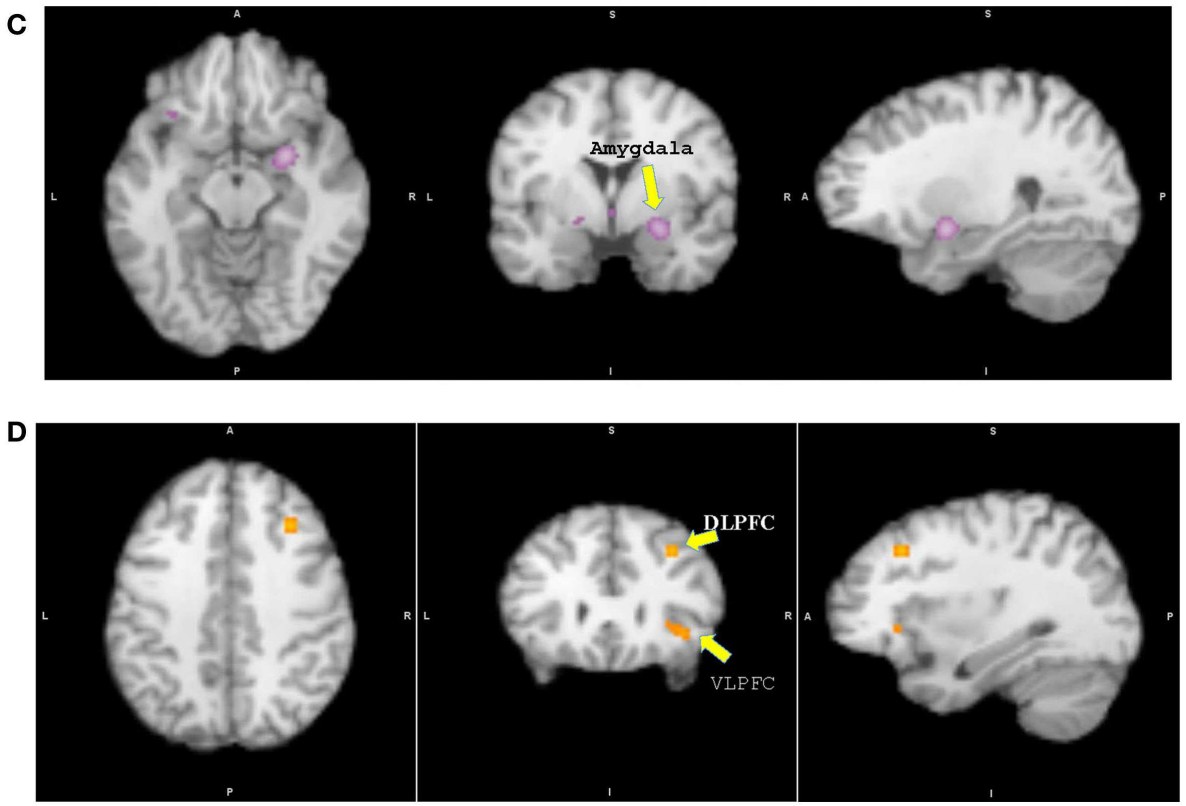

FIGURE 2 | Results from pairwise activation likelihood estimation (ALE) analysis. (A) High-risk youth > typically developing youth. (B) High-risk youth $>$ youth with bipolar disorder. (C) Youth with bipolar disorder > typically developing youth. (D) Typically developing youth $>$ youth with bipolar disorder. (A) DLPFC: dorsolateral prefrontal cortex, $x=46, y=8, z=22$, cluster size $=1048 \mathrm{~mm}^{3}$, extreme value $=0.020$; (B) DLPFC: $x=46, y=8, z=22$, cluster size $=1056 \mathrm{~mm}^{3}$, extreme value $=0.020$; (C) Amygdala: $x=26$, $y=-2, z=-12$, cluster size $=1120 \mathrm{~mm}^{3}$, extreme value $=0.022$; (D) DLPFC: $x=32, y=24, z=38$, cluster size $=224 \mathrm{~mm}^{3}$, extreme value $=0.013$; VLPFC: ventrolateral prefrontal cortex. and emotion-regulation circuits, together with an "overactive," left-sided ventral striatal-ventrolateral, and orbitofrontal cortical reward-processing circuit (58). These results attest to the fact that, in relative terms of group comparison from fMRI studies, cognitive DLPFC and the corresponding dorsal circuitry hub that includes the parietal region and the insula are more involved in the HR population, while the wider multiple cortico (VLPFC, DLPFC, and medial PFC) and subcortical (limbic and basal ganglia) regions are implicated in PBD.

Published structural and fMRI studies of HR have not been conclusive and are limited to a comparison with the TD at times (7, 11). Singh et al. (59) reported that 8- to 12-year-old children with a familial risk for mania did not exhibit any statistically significant volumetric differences in the PFC, thalamus, striatum, or amygdala 
compared with the TD group. However, they concluded that longitudinal studies will be needed to examine whether structural changes over time may be associated with a HR for BD (59). Bechdolf et al. (60) reported volume reduction in emotion-processing regions (i.e., the insula and amygdala) in $\mathrm{HR}$, relative to $\mathrm{TD}$, that corresponded to the functional abnormality involving increased amygdala activity in HR (9). While we found abnormal function in the insula in HR in this meta-analysis, three-way comparison did not reveal increased amygdala activity in HR. Existing studies consistently reported smaller amygdala and hippocampus (61), larger basal ganglia (62), and reduced PFC gray matter (63) in PBD. Hemodynamic (64) and resting state connectivity (65) findings in PBD relative to TD also point to frontolimbic and frontostriatal functional disturbance in PBD. Such uniformity in multi-modal imaging findings attests to the high reliability in establishing a significant pattern of brain dysfunction specific to PBD.

Limitations of this study include fewer and unequal numbers of participants in the HR group and the inclusion of studies that employed variable tasks used to probe multiple domains. However, due to the broad array of daily functions that draws from the active involvement of multiple and highly integrated networks, and the dual engagement of VLPFC, DLPFC, ACC, and the striatum in both cognitive and emotional tasks, this study was a reasonable first attempt to examine the entire brain's level of functionality from the existing data.

\section{ACKNOWLEDGMENTS}

We thank all the authors of the included published papers for their important contributions to the field. Support for this work was provided by endowed funds by the Colbeth Foundation and Berger-Colbeth Chair funds. All authors had full access to the data in the study. Dr. Pavuluri takes responsibility for directing the analysis and interpretation of the data. Dr. Moon-Soo Lee ensured the accuracy of the data analysis. Drs. Anumagalla, Talluri, and Lee entered the data and checked them for accuracy. Inclusion and exclusion criteria were applied following the full consensus of all authors.

\section{REFERENCES}

1. Baldessarini RJ, Tondo L, Vazquez GH, Undurraga J, Bolzani L, Yildiz A, et al. Age at onset versus family history and clinical outcomes in 1,665 international bipolar-I disorder patients. World Psychiatry (2012) 11(1):40-6. doi:10.1016/j. wpsyc.2012.01.006

2. Wozniak J, Petty CR, Schreck M, Moses A, Faraone SV, Biederman J. High level of persistence of pediatric bipolar-I disorder from childhood onto adolescent years: a four year prospective longitudinal follow-up study. J Psychiatr Res (2011) 45(10):1273-82. doi:10.1016/j.jpsychires.2010.10.006

3. Phillips ML, Kupfer DJ. Bipolar disorder diagnosis: challenges and future directions. Lancet (2013) 381(9878):1663-71. doi:10.1016/S0140-6736(13) 60989-7

4. Chang K, Karchemskiy A, Kelley R, Howe M, Garrett A, Adleman N, et al. Effect of divalproex on brain morphometry, chemistry, and function in youth at highrisk for bipolar disorder: a pilot study. J Child Adolesc Psychopharmacol (2009) 19(1):51-9. doi:10.1089/cap.2008.060

5. Deveney CM, Connolly ME, Jenkins SE, Kim P, Fromm SJ, Brotman MA, et al. Striatal dysfunction during failed motor inhibition in children at risk for bipolar disorder. Prog Neuropsychopharmacol Biol Psychiatry (2012) 38(2):127-33. doi:10.1016/j.pnpbp.2012.02.014

6. Kim P, Jenkins SE, Connolly ME, Deveney CM, Fromm SJ, Brotman MA, et al. Neural correlates of cognitive flexibility in children at risk for bipolar disorder. J Psychiatr Res (2012) 46(1):22-30. doi:10.1016/j.jpsychires.2011.09.015
7. Ladouceur CD, Diwadkar VA, White R, Bass J, Birmaher B, Axelson DA, et al. Fronto-limbic function in unaffected offspring at familial risk for bipolar disorder during an emotional working memory paradigm. Dev Cogn Neurosci (2013) 5:185-96. doi:10.1016/j.dcn.2013.03.004

8. Mourao-Miranda J, Oliveira L, Ladouceur CD, Marquand A, Brammer M, Birmaher B, et al. Pattern recognition and functional neuroimaging help to discriminate healthy adolescents at risk for mood disorders from low risk adolescents. PLoS One (2012) 7(2):e29482. doi:10.1371/journal.pone.0029482

9. Olsavsky AK, Brotman MA, Rutenberg JG, Muhrer EJ, Deveney CM, Fromm SJ, et al. Amygdala hyperactivation during face emotion processing in unaffected youth at risk for bipolar disorder. J Am Acad Child Adolesc Psychiatry (2012) 51(3):294-303. doi:10.1016/j.jaac.2011.12.008

10. Roberts G, Green MJ, Breakspear M, McCormack C, Frankland A, Wright A, et al. Reduced inferior frontal gyrus activation during response inhibition to emotional stimuli in youth at high risk of bipolar disorder. Biol Psychiatry (2013) 74(1):55-61. doi:10.1016/j.biopsych.2012.11.004

11. Thermenos HW, Makris N, Whitfield-Gabrieli S, Brown AB, Giuliano AJ, Lee $\mathrm{EH}$, et al. A functional MRI study of working memory in adolescents and young adults at genetic risk for bipolar disorder: preliminary findings. Bipolar Disord (2011) 13(3):272-86. doi:10.1111/j.1399-5618.2011.00920.x

12. Kober H, Wager TD. Meta-analysis of neuroimaging data. Wiley Interdiscip Rev Cogn Sci (2010) 1(2):293-300. doi:10.1002/wcs.41

13. Eickhoff SB, Laird AR, Grefkes C, Wang LE, Zilles K, Fox PT. Coordinate-based activation likelihood estimation meta-analysis of neuroimaging data: a randomeffects approach based on empirical estimates of spatial uncertainty. Hum Brain Mapp (2009) 30(9):2907-26. doi:10.1002/hbm.20718

14. Turkeltaub PE, Eickhoff SB, Laird AR, Fox M, Wiener M, Fox P. Minimizing within-experiment and within-group effects in activation likelihood estimation meta-analyses. Hum Brain Mapp (2012) 33(1):1-13. doi:10.1002/hbm.21186

15. Andreasen NC. Linking mind and brain in the study of mental illnesses: a project for a scientific psychopathology. Science (1997) 275(5306):1586-93. doi:10.1126/science.275.5306.1586

16. Kupferschmidt DA, Zakzanis KK. Toward a functional neuroanatomical signature of bipolar disorder: quantitative evidence from the neuroimaging literature. Psychiatry Res (2011) 193(2):71-9. doi:10.1016/j.pscychresns.2011.02.011

17. Pavuluri MN, Sweeney JA. Integrating functional brain neuroimaging and developmental cognitive neuroscience in child psychiatry research. J Am Acad Child Adolesc Psychiatry (2008) 47(11):1273-88. doi:10.1097/CHI.0b013e318185d2d1

18. Panksepp J. At the interface of the affective, behavioral, and cognitive neurosciences: decoding the emotional feelings of the brain. Brain Cogn (2003) 52(1):4-14. doi:10.1016/S0278-2626(03)00003-4

19. Pavuluri MN, O'Connor MM, Harral EM, Sweeney JA. An fMRI study of the interface between affective and cognitive neural circuitry in pediatric bipolar disorder. Psychiatry Res (2008) 162(3):244-55. doi:10.1016/j.pscychresns.2007. 10.003

20. Garrett AS, Reiss AL, Howe ME, Kelley RG, Singh MK, Adleman NE, et al. Abnormal amygdala and prefrontal cortex activation to facial expressions in pediatric bipolar disorder. J Am Acad Child Adolesc Psychiatry (2012) 51(8):821-31. doi:10.1016/j.jaac.2012.06.005

21. Pavuluri MN, Passarotti AM, Harral EM, Sweeney JA. An fMRI study of the neural correlates of incidental versus directed emotion processing in pediatric bipolar disorder. J Am Acad Child Adolesc Psychiatry (2009) 48(3):308-19. doi:10.1097/CHI.0b013e3181948fc7

22. Passarotti AM, Sweeney JA, Pavuluri MN. Emotion processing influences working memory circuits in pediatric bipolar disorder and attentiondeficit/hyperactivity disorder. J Am Acad Child Adolesc Psychiatry (2010) 49(10):1064-80. doi:10.1016/j.jaac.2010.07.009

23. Rich BA, Vinton DT, Roberson-Nay R, Hommer RE, Berghorst LH, McClure EB, et al. Limbic hyperactivation during processing of neutral facial expressions in children with bipolar disorder. Proc Natl Acad Sci U S A (2006) 103(23):8900-5. doi:10.1073/pnas.0603246103

24. Cerullo MA, Adler CM, Lamy M, Eliassen JC, Fleck DE, Strakowski SM, et al. Differential brain activation during response inhibition in bipolar and attentiondeficit hyperactivity disorders. Early Interv Psychiatry (2009) 3(3):189-97. doi:10.1111/j.1751-7893.2009.00132.x

25. Chang K, Adleman NE, Dienes K, Simeonova DI, Menon V, Reiss A. Anomalous prefrontal-subcortical activation in familial pediatric bipolar disorder: a functional magnetic resonance imaging investigation. Arch Gen Psychiatry (2004) 61(8):781-92. doi:10.1001/archpsyc.61.8.781 
26. Deveney CM, Connolly ME, Jenkins SE, Kim P, Fromm SJ, Pine DS, et al. Neural recruitment during failed motor inhibition differentiates youths with bipolar disorder and severe mood dysregulation. Biol Psychol (2012) 89(1):148-55. doi:10.1016/j.biopsycho.2011.10.003

27. Dickstein DP, Finger EC, Skup M, Pine DS, Blair JR, Leibenluft E. Altered neural function in pediatric bipolar disorder during reversal learning. Bipolar Disord (2010) 12(7):707-19. doi:10.1111/j.1399-5618.2010.00863.x

28. Dickstein DP, Rich BA, Roberson-Nay R, Berghorst L, Vinton D, Pine DS, et al. Neural activation during encoding of emotional faces in pediatric bipolar disorder. Bipolar Disord (2007) 9(7):679-92. doi:10.1111/j.1399-5618.2007. 00418.x

29. Diler RS, Ladouceur CD, Segreti A, Almeida JR, Birmaher B, Axelson DA, et al. Neural correlates of treatment response in depressed bipolar adolescents during emotion processing. Brain Imaging Behav (2013) 7(2):227-35. doi:10.1007/s11682-012-9219-7

30. Diler RS, Segreti AM, Ladouceur CD, Almeida JR, Birmaher B, Axelson DA, et al. Neural correlates of treatment in adolescents with bipolar depression during response inhibition. J Child Adolesc Psychopharmacol (2013) 23(3):214-21. doi:10.1089/cap.2012.0054

31. Kim P, Thomas LA, Rosen BH, Moscicki AM, Brotman MA, Zarate CA Jr, et al. Differing amygdala responses to facial expressions in children and adults with bipolar disorder. Am J Psychiatry (2012) 169(6):642-9. doi:10.1176/appi.ajp. 2012.11081245

32. Leibenluft E, Rich BA, Vinton DT, Nelson EE, Fromm SJ, Berghorst LH, et al. Neural circuitry engaged during unsuccessful motor inhibition in pediatric bipolar disorder. Am J Psychiatry (2007) 164(1):52-60. doi:10.1176/appi.ajp. 164.1 .52

33. Nelson EE, Vinton DT, Berghorst L, Towbin KE, Hommer RE, Dickstein DP, et al. Brain systems underlying response flexibility in healthy and bipolar adolescents: an event-related fMRI study. Bipolar Disord (2007) 9(8):810-9. doi:10.1111/j.1399-5618.2007.00419.x

34. Passarotti AM, Sweeney JA, Pavuluri MN. Neural correlates of response inhibition in pediatric bipolar disorder and attention deficit hyperactivity disorder. Psychiatry Res (2010) 181(1):36-43. doi:10.1016/j.pscychresns.2009.07.002

35. Passarotti AM, Sweeney JA, Pavuluri MN. Differential engagement of cognitive and affective neural systems in pediatric bipolar disorder and attention deficit hyperactivity disorder. J Int Neuropsychol Soc (2010) 16(1):106-17. doi:10.1017/S1355617709991019

36. Passarotti AM, Sweeney JA, Pavuluri MN. Fronto-limbic dysfunction in mania pre-treatment and persistent amygdala over-activity post-treatment in pediatric bipolar disorder. Psychopharmacology (Berl) (2011) 216(4):485-99. doi:10.1007/ s00213-011-2243-2

37. Pavuluri MN, O’Connor MM, Harral E, Sweeney JA. Affective neural circuitry during facial emotion processing in pediatric bipolar disorder. Biol Psychiatry (2007) 62(2):158-67. doi:10.1016/j.biopsych.2006.07.011

38. Pavuluri MN, Passarotti AM, Harral EM, Sweeney JA. Enhanced prefrontal function with pharmacotherapy on a response inhibition task in adolescent bipolar disorder. J Clin Psychiatry (2010) 71(11):1526-34. doi:10.4088/JCP. 09m05504yel

39. Pavuluri MN, Passarotti AM, Parnes SA, Fitzgerald JM, Sweeney JA. A pharmacological functional magnetic resonance imaging study probing the interface of cognitive and emotional brain systems in pediatric bipolar disorder. J Child Adolesc Psychopharmacol (2010) 20(5):395-406. doi:10.1089/cap.2009.0105

40. Singh MK, Chang KD, Kelley RG, Cui X, Sherdell L, Howe ME, et al. Reward processing in adolescents with bipolar I disorder. J Am Acad Child Adolesc Psychiatry (2013) 52(1):68-83. doi:10.1016/j.jaac.2012.10.004

41. Singh MK, Chang KD, Mazaika P, Garrett A, Adleman N, Kelley R, et al. Neural correlates of response inhibition in pediatric bipolar disorder. J Child Adolesc Psychopharmacol (2010) 20(1):15-24. doi:10.1089/cap.2009.0004

42. Weathers JD, Stringaris A, Deveney CM, Brotman MA, Zarate CA Jr, Connolly ME, et al. A developmental study of the neural circuitry mediating motor inhibition in bipolar disorder. Am J Psychiatry (2012) 169(6):633-41. doi:10.1176/appi.ajp.2012.11081244

43. Eickhoff SB, Bzdok D, Laird AR, Kurth F, Fox PT. Activation likelihood estimation meta-analysis revisited. Neuroimage (2012) 59(3):2349-61. doi:10.1016/j. neuroimage.2011.09.017

44. Brett M, Johnsrude IS, Owen AM. The problem of functional localization in the human brain. Nat Rev Neurosci (2002) 3(3):243-9. doi:10.1038/nrn756
45. Laird AR, Fox PM, Price CJ, Glahn DC, Uecker AM, Lancaster JL, et al. ALE metaanalysis: controlling the false discovery rate and performing statistical contrasts. Hum Brain Mapp (2005) 25(1):155-64. doi:10.1002/hbm.20136

46. Wegbreit E, Cushman GK, Puzia ME, Weissman AB, Kim KL, Laird AR, et al. Developmental meta-analyses of the functional neural correlates of bipolar disorder. JAMA Psychiatry (2014) 71(8):926-35. doi:10.1001/jamapsychiatry. 2014.660

47. Correll CU, Hauser M, Penzner JB, Auther AM, Kafantaris V, Saito E, et al. Type and duration of subsyndromal symptoms in youth with bipolar I disorder prior to their first manic episode. Bipolar Disord (2014) 16(5):478-92. doi:10.1111/bdi.12194

48. Pavuluri M. Neurobiology of bipolar disorder in youth: brain domain dysfunction is translated to decode the pathophysiology and understand the nuances of the clinical manifestation. In: Strakowski SM, DelBello MP, Adler CM, editors. Bipolar Disorder in Youth. New York: Oxford University Press (2014). p. 282-304.

49. Passarotti AM, Sweeney JA, Pavuluri MN. Neural correlates of incidental and directed facial emotion processing in adolescents and adults. Soc Cogn Affect Neurosci (2009) 4(4):387-98. doi:10.1093/scan/nsp029

50. Goya-Maldonado R, Walther S, Simon J, Stippich C, Weisbrod M, Kaiser S. Motor impulsivity and the ventrolateral prefrontal cortex. Psychiatry Res (2010) 183(1):89-91. doi:10.1016/j.pscychresns.2010.04.006

51. Banks SJ, Eddy KT, Angstadt M, Nathan PJ, Phan KL. Amygdala-frontal connectivity during emotion regulation. Soc Cogn Affect Neurosci (2007) 2(4):303-12. doi:10.1093/scan/nsm029

52. Leh SE, Ptito A, Chakravarty MM, Strafella AP. Fronto-striatal connections in the human brain: a probabilistic diffusion tractography study. Neurosci Lett (2007) 419(2):113-8. doi:10.1016/j.neulet.2007.04.049

53. Duncan J, Owen AM. Common regions of the human frontal lobe recruited by diverse cognitive demands. Trends Neurosci (2000) 23(10):475-83. doi:10.1016/ S0166-2236(00)01633-7

54. Chudasama Y, Robbins TW. Functions of frontostriatal systems in cognition: comparative neuropsychopharmacological studies in rats, monkeys and humans. Biol Psychol (2006) 73(1):19-38. doi:10.1016/j.biopsycho.2006.01.005

55. Rogers RD, Ramnani N, Mackay C, Wilson JL, Jezzard P, Carter CS, et al. Distinct portions of anterior cingulate cortex and medial prefrontal cortex are activated by reward processing in separable phases of decision-making cognition. Biol Psychiatry (2004) 55(6):594-602. doi:10.1016/j.biopsych.2003.11.012

56. Cavada C, Company T, Tejedor J, Cruz-Rizzolo RJ, Reinoso-Suarez F. The anatomical connections of the macaque monkey orbitofrontal cortex. A review. Cereb Cortex (2000) 10(3):220-42. doi:10.1093/cercor/10.3.220

57. Rich BA, Holroyd T, Carver FW, Onelio LM, Mendoza JK, Cornwell BR, et al. A preliminary study of the neural mechanisms of frustration in pediatric bipolar disorder using magnetoencephalography. Depress Anxiety (2010) 27(3):276-86. doi:10.1002/da.20649

58. Phillips ML, Swartz HA. A critical appraisal of neuroimaging studies of bipolar disorder: toward a new conceptualization of underlying neural circuitry and a road map for future research. Am J Psychiatry (2014) 171(8):829-43. doi:10.1176/appi.ajp.2014.13081008

59. Singh MK, Delbello MP, Adler CM, Stanford KE, Strakowski SM. Neuroanatomical characterization of child offspring of bipolar parents. J Am Acad Child Adolesc Psychiatry (2008) 47(5):526-31. doi:10.1097/CHI.0b013e318167655a

60. Bechdolf A, Wood SJ, Nelson B, Velakoulis D, Yucel M, Takahashi T, et al. Amygdala and insula volumes prior to illness onset in bipolar disorder: a magnetic resonance imaging study. Psychiatry Res (2012) 201(1):34-9. doi:10.1016/ j.pscychresns.2011.06.010

61. Blumberg HP, Kaufman J, Martin A, Whiteman R, Zhang JH, Gore JC, et al. Amygdala and hippocampal volumes in adolescents and adults with bipolar disorder. Arch Gen Psychiatry (2003) 60(12):1201-8. doi:10.1001/archpsyc.60.12. 1201

62. DelBello MP, Zimmerman ME, Mills NP, Getz GE, Strakowski SM. Magnetic resonance imaging analysis of amygdala and other subcortical brain regions in adolescents with bipolar disorder. Bipolar Disord (2004) 6(1):43-52. doi:10.1046/j.1399-5618.2003.00087.x

63. Dickstein DP, Milham MP, Nugent AC, Drevets WC, Charney DS, Pine DS, et al. Frontotemporal alterations in pediatric bipolar disorder: results of a voxel-based morphometry study. Arch Gen Psychiatry (2005) 62(7):734-41. doi:10.1001/archpsyc.62.7.734 
64. Wegbreit E, Passarotti AM, Ellis JA, Wu M, Witowski N, Fitzgerald JM, et al. Where, when, how high, and how long? The hemodynamics of emotional response in psychotropic-naive patients with adolescent bipolar disorder. JAffect Disord (2013) 147(1-3):304-11. doi:10.1016/j.jad.2012.11.025

65. Wu M, Lu LH, Passarotti AM, Wegbreit E, Fitzgerald J, Pavuluri MN. Altered affective, executive and sensorimotor resting state networks in patients with pediatric mania. J Psychiatry Neurosci (2013) 38(4):232-40. doi:10.1503/jpn. 120073

Conflict of Interest Statement: The authors declare that the research was conducted in the absence of any commercial or financial relationships that could be construed as a potential conflict of interest.
Received: 10 June 2014; accepted: 24 September 2014; published online: 03 November 2014.

Citation: Lee M-S, Anumagalla P, Talluri P and Pavuluri MN (2014) Meta-analyses of developing brain function in high-risk and emerged bipolar disorder. Front. Psychiatry 5:141. doi: 10.3389/fpsyt.2014.00141

This article was submitted to Neuropsychiatric Imaging and Stimulation, a section of the journal Frontiers in Psychiatry.

Copyright $(2014$ Lee, Anumagalla, Talluri and Pavuluri. This is an open-access article distributed under the terms of the Creative Commons Attribution License (CC $B Y)$. The use, distribution or reproduction in other forums is permitted, provided the original author(s) or licensor are credited and that the original publication in this journal is cited, in accordance with accepted academic practice. No use, distribution or reproduction is permitted which does not comply with these terms. 